WSRC-STI-2007-00352

Rev. 0

\title{
SALTSTONE VARIABILITY STUDY - MEASUREMENT OF POROSITY
}

\author{
J. R. Harbour, V. J. Williams, T. B. Edwards, \\ R. E. Eibling and R. F. Schumacher \\ Savannah River National Laboratory
}

August 2007

Process Science and Engineering

Savannah River National Laboratory Aiken, SC 29808 


\section{DISCLAIMER}

This report was prepared by Washington Savannah River Company (WSRC) for the United States Department of Energy under Contract No. DE-AC09-96SR18500 and is an account of work performed under that contract. Neither the United States Department of Energy, nor WSRC, nor any of their employees makes any warranty, expressed or implied, or assumes any legal liability or responsibility for the accuracy, completeness, or usefulness, of any information, apparatus, or product or process disclosed herein or represents that its use will not infringe privately owned rights. Reference herein to any specific commercial product, process, or service by trademark, name, manufacturer or otherwise does not necessarily constitute or imply endorsement, recommendation, or favoring of same by WSRC or by the United States Government or any agency thereof. The views and opinions of the authors expressed herein do not necessarily state or reflect those of the United States Government or any agency thereof.

\section{Printed in the United States of America}

Prepared For

U.S. Department of Energy 
WSRC-STI-2007-00352

Rev. 0

Key Words: Fly Ash

Portland Cement

Blast Furnace Slag

Retention: Permanent

\title{
SALTSTONE VARIABILITY STUDY - MEASUREMENT OF POROSITY
}

\author{
J. R. Harbour, V. J. Williams, T. B. Edwards, \\ R. E. Eibling and R. F. Schumacher
}

Savannah River National Laboratory

July 2007

Process Science and Engineering Savannah River National Laboratory Aiken, SC 29808

Prepared for the U.S. Department of Energy Under Contract Number DEAC09-96SR18500 


\section{REVIEWS AND APPROVALS}

\section{AUTHORS:}

J. R. Harbour, SRNL, Stabilization Science Research

Date

V. J. Williams, SRNL, Stabilization Science Research

Date

T. B. Edwards, SRNL, Computational and Statistical Science

Date

R. E. Eibling, SRNL, Advanced Process Development

Date

R. F. Schumacher, SRNL, Advanced Process Development

Date

\section{TECHNICAL REVIEWERS:}

A. D. Cozzi, SRNL, Stabilization Science Research

Date

\section{APPROVERS}

D. A. Crowley, SRNL, Manager, Stabilization Science Research

Date

R. E. Edwards, SRNL, Manager, Process Science and Engineering

Date

J. E. Occhipinti, Manager, Waste Solidification Engineering

Date 


\section{EXECUTIVE SUMMARY}

One of the goals of the Saltstone Variability Study is to identify the operational and compositional variables that control or influence the important processing and performance properties of Saltstone mixes. One of the key performance properties is porosity which is a measure of the volume percent of a cured grout that is occupied by salt solution (for the saturated case). This report presents (1) the results of efforts to develop a method for the measurement of porosity of grout samples and (2) initial results of porosity values for samples that have been previously produced as part of the Saltstone Variability Study.

A cost effective measurement method for porosity was developed that provides reproducible results, is relatively fast (30 to 60 minutes per sample) and uses a Mettler Toledo HR83 Moisture Analyzer that is already operational and routinely calibrated at Aiken County Technology Laboratory. The method involves the heating of the sample at $105{ }^{\circ} \mathrm{C}$ until no further mass loss is observed. This mass loss value, which is due to water evaporation, is then used to calculate the volume percent porosity of the mix.

The results of mass loss for mixes at $105{ }^{\circ} \mathrm{C}$ were equivalent to the results obtained using thermal gravimetric analysis. The method was validated by comparing measurements of mass loss at 105 ${ }^{\circ} \mathrm{C}$ for cured portland cement in water mixes to values presented in the literature for this system.

A stereopycnometer from Quantachrome Instruments was selected to measure the cured grout bulk densities. Density is a property that is required to calculate the porosities. A stereopycnometer was already operational at Aiken County Technology Laboratory, has been calibrated using a solid stainless steel sphere of known volume, is cost effective and fast $(\sim 15$ minutes per sample). Cured grout densities are important in their own right because they can be used to project the volume of waste form produced from a given amount of salt feed of known composition.

For mixes made from either Modular Caustic Side Solvent Extraction Unit (MCU) or Salt Waste Processing Facility (SWPF) simulants in premix, the porosities averaged near $62 \%$ with an uptake of water through hydration reactions equivalent to a water to cementitious materials ratio $(\mathrm{w} / \mathrm{cm})$ of 0.04 . For a mix made from a Deliquification, Dissolution and Adjustment (DDA) simulant and premix, the porosity is slightly lower at $57 \%$ with an uptake of water through hydration reactions equivalent to a $\mathrm{w} / \mathrm{cm}$ ratio of 0.07 . Data are presented which demonstrate that porosity is inversely related to the heat of hydration, a measure of the extent of the hydration reactions.

Modeling of porosities from three of the statistically designed phases of the Saltstone Variability Study demonstrated that the data could be fit to a linear model with an $\mathrm{R}^{2}$ of 0.74 and no statistical evidence for a lack of fit. The model revealed that $\mathrm{w} / \mathrm{cm}$ ratio plays a significant role in the total porosity with porosity increasing as the $\mathrm{w} / \mathrm{cm}$ ratio increases. Other elements of the model include positive correlations with the free hydroxide ion concentration and the total nitrate plus nitrite ion concentration. For a series of mixes in which the composition of the salt solution remained constant (MCU baseline) the porosity increased from $\sim 60$ to $65 \%$ as the $\mathrm{w} / \mathrm{cm}$ ratio increased from 0.55 to 0.65 


\section{TABLE OF CONTENTS}

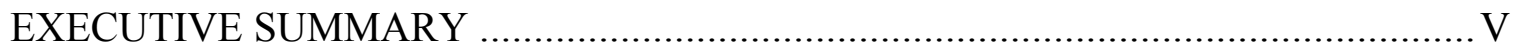

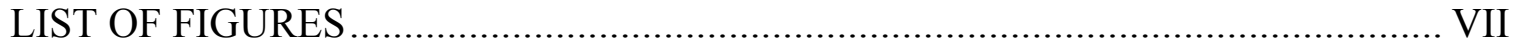

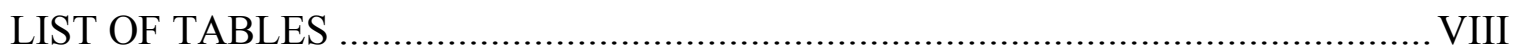

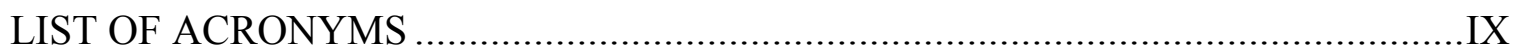

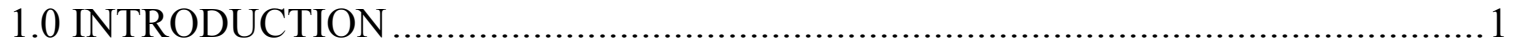

2.0 EXPERIMENTAL

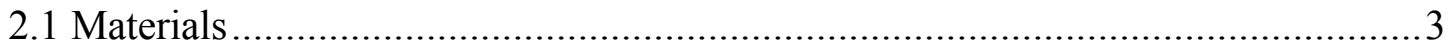

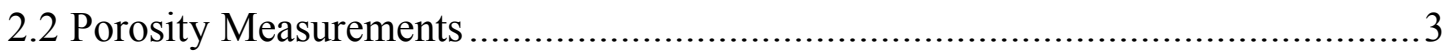

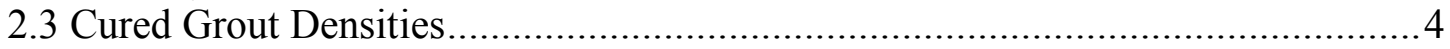

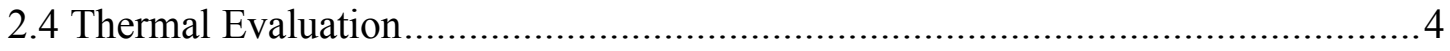

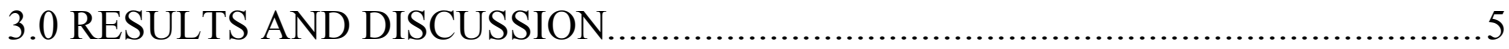

3.1 Measurement Reproducibility of Porosity and Cured Grout Density ......................5

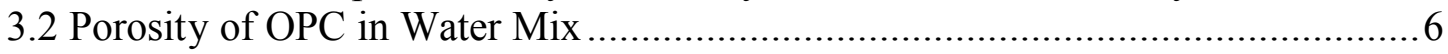

3.3 Porosities of Grouts Prepared from OPC and GGBFS in MCU Simulant.............. 7

3.4 Porosities of Grouts Prepared from Premix in DDA, MCU and SWPF Simulants. 8

3.5 Comparison of TGA and Mass Loss at $105^{\circ} \mathrm{C}$.............................................. 10

3.6 Modeling of Porosity - Saltstone Variability Study ………................................ 12

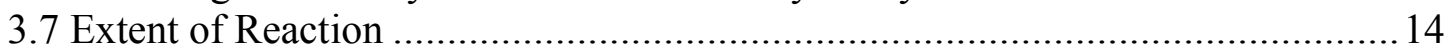

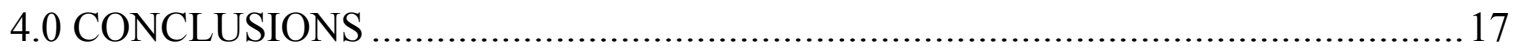

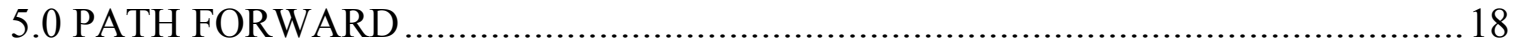

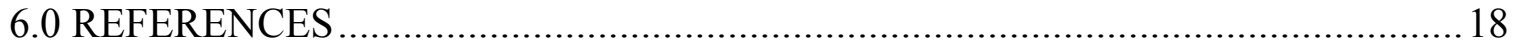




\section{LIST OF FIGURES}

Figure 3-1 TGA results for TR258 sample of premix and MCU simulant at $0.60 \mathrm{w} / \mathrm{cm}$ ratio 11

Figure 3-2 TGA results for a premix in water grout

Figure 3-3 Linear model for the total porosity as a function of $\mathrm{w} / \mathrm{cm}$, free hydroxide ion concentration and total nitrate plus nitrite concentration measured at $25^{\circ} \mathrm{C}$

Figure 3-4 Linear dependence of the total porosity for MCU based simulant mixes on the w/cm ratio at $25^{\circ} \mathrm{C}$

Figure 3-5 Porosity vs. heat of hydration in Joules/gram of cementitious material

Figure 3-6 Plot of extent of reaction (expressed here as the hydration $\mathrm{w} / \mathrm{cm}$ ratio) vs. heat of hydration in Joules/gram of cementitious material 


\section{LIST OF TABLES}

Table 3-1 Porosities and Cured Grout Densities for 5 Sealed Gel Samples of GVS 77 Measured after 38 Days of Curing at Ambient Temperature .................................................... 5

Table 3-2 Total Porosity of Cured Mixes of Water in OPC ................................................. 6

Table 3-3 Porosities of Mixes Containing OPC in MCU Simulant as a Function of Curing Time 7

Table 3-4 Porosities of Mixes Containing GGBFS in MCU Simulant as a Function of Curing

Time

Table 3-5 Porosities of Mixes Containing Either OPC or GGBFS in DDA Simulant................. 8

Table 3-6 Results of the Measured Porosity and Maximum Porosity for Mixes Made from

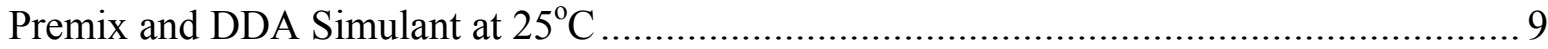

Table 3-7 Results of the Measured Porosity and Maximum Porosity for Mixes Made from

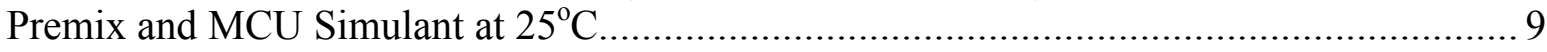

Table 3-8 Results of the Measured Porosity and Maximum Porosity for Mixes Made from

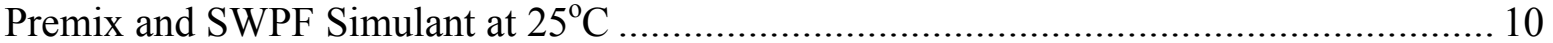

Table 3-9 Heat of Hydration, Porosity and Hydration w/cm ratio ...................................... 14

Table 3-10 The Percentages of Free Water and Bound Water in the Grout Mixes Prepared at 0.60

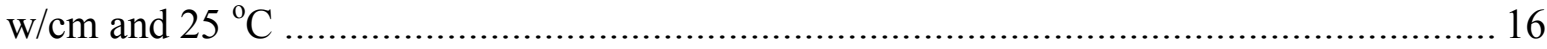


Rev. 0

\section{LIST OF ACRONYMS}

\begin{tabular}{|l|l|}
\hline ACTL & Aiken County Technology Laboratory \\
\hline ASTM & American Society for Testing and Materials \\
\hline CSH & Calcium Silicate Hydrate \\
\hline DDA & Deliquification, Dissolution and Adjustment \\
\hline FA & Fly Ash \\
\hline GGBFS & Ground Granulated Blast Furnace Slag \\
\hline MCU & Modular Caustic Side Solvent Extraction Unit \\
\hline OPC & Ordinary Portland Cement \\
\hline SRNL & Savannah River National Laboratory \\
\hline SRS & Savannah River Site \\
\hline SDF & Saltstone Disposal Facility \\
\hline SPF & Saltstone Processing Facility \\
\hline SWPF & Salt Waste Processing Facility \\
\hline TGA & Thermogravimetric Analysis \\
\hline TR & Trial Run \\
\hline
\end{tabular}




\subsection{INTRODUCTION}

One of the goals of the variability study is to identify the operational and compositional variables that control the important processing and performance properties of Saltstone mixes [1]. As part of this task, a method was needed to measure the porosity of the mixes. Porosity is an important performance parameter that provides a quantitative estimate on the extent of reaction (hydration) of the cementitious materials and correlates to the permeability (in this case, hydraulic conductivity, an input parameter to the Performance Assessment) of the cured mixes. For example, if the pores within a mix are connected (which tends to occur for mixes with higher porosity), then conductivity of a fluid through the pore structure (referred to as percolation) is facilitated and the hydraulic conductivity will be high. Establishing an acceptance criterion for hydraulic conductivity based on porosity as measured in this report has the potential to provide a routine method to ensure that simulated and/or radioactive mixes comply with requirements.

A method for determining total porosity of cured grout or concrete mixes was required that provides values that are consistent with accepted values, can be readily performed on each mix from the variability study in a reasonable time and has a low cost for setup and testing.

Grout porosity is generally defined as the percentage of total volume of cured grout that is not occupied by either the starting cementitious materials (in this case, portland cement, blast furnace slag, and Class F fly ash) and the products that results from reaction of these cementitious materials with water (calcium silicate hydrate $(\mathrm{CSH})$ and calcium hydroxide crystals). For Saltstone mixes, the pore volume is occupied by a concentrated salt solution.

The total porosity can be divided into capillary pores and gel pores (much smaller in dimension) [2]. For example the Powers and Brownyard model [3] predicts a gel porosity of $23 \%$ and a capillary porosity of $24 \%$ for a fully reacted portland cement in water mix with a water to cement ratio of 0.60 . The total porosity is predicted therefore to be $47 \%$ which is equivalent to saying that $47 \%$ of the cured portland cement paste is occupied by water for the saturated case. The total porosity for this case has been experimentally determined to be close to $47 \%[3,4]$.

A number of methods have been used to measure the porosities and pore size distributions of concretes and grouts [2,5]. The measurements are not always straight forward, and there are variations in the results from the different techniques. This report does not address the measurement of pore size distributions which have been studied by mercury intrusion porosimetry [6], scanning electron microscopy, AC impedance spectroscopy, small angle X-ray and neutron scattering, proton nuclear magnetic resonance and low temperature calorimetry [7]. Rather, this report addresses the measurement of total porosity.

Total porosity has been measured by drying at room temperature (D-drying), heating to a higher temperature until no further mass loss is observed, and by replacing the pore solution with a solvent [2]. Typically, the temperature of choice for drying at higher temperatures is $105{ }^{\circ} \mathrm{C}$ [8] although some authors prefer $60{ }^{\circ} \mathrm{C}$ [9]. For Saltstone mixes, the proposed method of total porosity measurement is to heat to $105^{\circ} \mathrm{C}$ until no further mass loss is observed. The wt \% 
solids apparatus already available and operational at Aiken County Technology Laboratory (ACTL), automatically calculates the mass loss at the desired temperature (in this case $105^{\circ} \mathrm{C}$ ) after no further change in mass occurs. Total time for each measurement (done is duplicate) is typically between 30 to 60 minutes depending on the size of the grout pieces.

Implicit in this calculation is the assumption that a method for the determination of the density of the cured grout is available. The density is required to determine the volume of the grout in order to calculate the porosity. To measure the cured grout density, a pycnometer already installed and operational at ACTL was selected. This technique was evaluated and subsequently used for density measurements for this task. Cured grout density is also an important property of the cured grout in its own right for example in determining the volume of grout that will be produced from a given volume of salt solution. 


\subsection{EXPERIMENTAL}

\subsection{Materials}

The cementitious materials were obtained from Z-Area. These materials were specified in a WSRC contract for Saltstone cementitious materials and arrived with the delivery of the cementitious materials to Saltstone. The materials were transferred to 2 liter plastic bottles at ACTL and tightly sealed. The seal limits the amount of exposure the materials get to the air and associated humidity.

\section{Material}

Portland cement (OPC)

Blast Furnace slag (GGBFS)

Fly ash (FA)

\begin{tabular}{ll} 
Category & Vendor \\
\hline Type II & Holcim \\
Grade I or II & Holcim \\
Class F & Cross Station
\end{tabular}

The deliquification, dissolution and adjustment (DDA), modular caustic side solvent extraction unit (MCU) and salt waste processing facility (SWPF) simulants were batched to the compositions presented in previous reports $[10,11]$. The mixing was performed as previously described using a paddle blade mixer with a three minute mixing duration [10].

\subsection{Porosity Measurements}

The porosity was determined by the mass loss upon heating samples (1.5 to 2 grams) to $105^{\circ} \mathrm{C}$ using a Mettler Toledo HR83 Moisture Analyzer. This instrument measures mass loss as a function of time until no further mass loss is observed. The typical time for measurement is on the order of 30 minutes but can be up to one hour if the cured grout is not broken into smaller pieces. The grout pieces that were used in the measurement of porosity were taken from the center of the cylinder by breaking the cylinder and removing pieces from the center region.

The total porosity is defined here as the percentage of total volume occupied by the pore solution for the saturated case. For example, a grout which contains $45 \%$ by volume of simulated salt solution has a total porosity of $45 \%$.

For a grout that is composed only of water and cementitious material, the weight loss at $105{ }^{\circ} \mathrm{C}$ can be converted to a volume of water by dividing by $1.0 \mathrm{~g} / \mathrm{mL}$. The porosity is then calculated by dividing this volume by the overall volume of the grout. For Saltstone solutions, the mass of water released during heating to $105{ }^{\circ} \mathrm{C}$ is converted to a volume of pore solution by first dividing by the ratio of the mass of water to the mass of simulant (e.g., 0.68 for MCU simulant) and then dividing again by the density of the simulant (e.g., $1.26 \mathrm{~g} / \mathrm{mL}$ for MCU simulant).

The theoretical maximum porosity is calculated by dividing the volume of simulant introduced into a mix by the overall volume of grout that will be produced from this mix after curing. 


\subsection{Cured Grout Densities}

The cured grout densities were measured using a stereopycnometer from Quantachrome Instruments, Model Number SPY-5DC. The grout was removed from the plastic cylinder in which it had cured and immediately placed as one piece into the cup of the pycnometer. Typically, the cylinder mass was $\sim 100$ grams. The results for the measurement of the volume of the mass were an average of three separate measurements. The density was then calculated from this average volume and the measured mass. Nitrogen was used as the gas for the density measurements.

The stereopycnometer was calibrated using a metal sphere of known volume. This sphere was measured each day both before and after measuring the samples. The volume of the cup without the sphere was also measured as a check on the system.

\subsection{Thermal Evaluation}

A Netzsch STA 409 PC thermal analyzer was used to measure the mass change with temperature (referred to as Thermogravimetric Analysis or TGA) up to $\sim 800{ }^{\circ} \mathrm{C}$. 


\subsection{RESULTS AND DISCUSSION}

The measurement reproducibility of the porosity (and cured grout density) was determined for a given batch of Saltstone and the results are presented in Section 3.1.

In order to provide insight into the contributions of OPC, GGBFS and the type of salt solution to the measured total porosities of Saltstone mixes, porosities were initially measured on mixes prepared using OPC in water, OPC in MCU simulant and GGBFS in MCU simulant. These data are provided in Sections 3.2 and 3.3.

Next, the porosity measurements are presented from mixes prepared using the baseline premix material with a mass ratio of $45 \%$ GGBFS, $45 \%$ FA and $10 \%$ OPC in simulants of DDA, MCU and SWPF (Section 3.4).

Finally, three sections are provided that detail a comparison of the TGA results with the mass loss at $105{ }^{\circ} \mathrm{C}$ (Section 3.5), modeling of the porosity (Section 3.6) and extent of hydration reactions (Section 3.7).

\subsection{Measurement Reproducibility of Porosity and Cured Grout Density}

The measurement reproducibility of porosity using mass loss at $105^{\circ} \mathrm{C}$ and cured grout density using pcynometry were determined using 5 samples from a single batch of GVS 77 (SWPF). The data for these 5 samples are provided in Table 3-1. These samples had cured for 38 days under sealed conditions and ambient temperature prior to the measurements of densities and porosities.

Table 3-1 Porosities and Cured Grout Densities for 5 Sealed Samples of GVS 77 Measured after 38 Days of Curing at Ambient Temperature

\begin{tabular}{|c|c|c|c|}
\hline Sample \# & Density & \% Wt Loss & Porosity \\
\hline 1 & 1.829 & 28.66 & 62.92 \\
\hline 2 & 1.822 & 28.64 & 62.64 \\
\hline 3 & 1.830 & 28.46 & 62.51 \\
\hline 4 & 1.826 & 28.17 & 61.74 \\
\hline 5 & 1.821 & 28.31 & 61.88 \\
\hline Average & 1.826 & 28.45 & 62.34 \\
\hline SD & 0.004 & 0.21 & 0.51 \\
\hline
\end{tabular}

The porosities for each sample were calculated using the measured $\% \mathrm{Wt}$. loss values and cured grout densities for each sample. The relative standard deviation for porosity is $0.82 \%$ and 0.22 $\%$ for cured grout density. 


\subsection{Porosity of OPC in Water Mix}

Mixes of OPC in water were prepared using a conventional paddle blade mixer for three minutes at $\sim 25{ }^{\circ} \mathrm{C}$ with a water to OPC ratio $(\mathrm{w} / \mathrm{c})$ of 0.60 . Table $3-2$ presents porosities measured for $\mathrm{OPC}$ in water as a function of cure time and temperature of curing. The first four entries were samples obtained from the same batch (TR 311) but with different curing conditions. The last two entries were from measurements of samples that had been used to measure the heat of hydration by isothermal calorimetry.

The porosities measured for TR 311-1 and TR 311-4 were essentially equivalent. The only difference between these two samples was the addition of extra water to the top of the TR 311-4 sample before sealing. When the sample was cured without sealing under ambient conditions, the sample surface dried out and the measured density was higher although the porosity was nearly the same as TR 311-1. Heating the sealed TR 311-3 sample in an oven for 8 days at 70 ${ }^{\circ} \mathrm{C}$ resulted in a lower porosity and lower cured density.

Table 3-2 Total Porosity of Cured Mixes of Water in OPC

\begin{tabular}{|c|c|c|c|c|c|c|c|c|}
\hline Sample ID & Curing & Curing & Cure Time & Cured & w/cm & Porosity & Porosity & W/cm \\
\hline & Conditions & Temperature & Days & Density & Batched & Measured & Maximum & hydration \\
\hline TR311-1 & Sealed & 25 & 8 & 1.87 & 0.60 & 52.0 & 70.1 & 0.16 \\
\hline TR311-2 & Open & 25 & 8 & 1.95 & 0.60 & 51.0 & 73.1 & 0.18 \\
\hline TR311-3 & Sealed & 70 & 8 & 1.82 & 0.60 & 47.0 & 68.3 & 0.18 \\
\hline TR311-4 & Added $\mathrm{H}_{2} \mathrm{O}$ & 25 & 9 & 1.88 & 0.60 & 52.0 & 70.7 & 0.16 \\
\hline TR298-A & Sealed & 40 & 47 & $1.82^{*}$ & 0.60 & 49.7 & 68.3 & 0.16 \\
\hline TR302-A & Sealed & 55 & 37 & $1.82^{*}$ & 0.60 & 47.6 & 68.3 & 0.18 \\
\hline
\end{tabular}

Assumed density equivalent to TR311-3

The last two samples were extracted from the vials used for the heat of hydration measurements. Consequently, no density measurements could be performed on these small samples prior to porosity measurements. Therefore, the density was assumed to be equal to that of sample TR 311-3. In these samples, the curing temperature was held for 7 days (for the heat of hydration measurement) prior to storage at ambient temperature. The sample heated to $55{ }^{\circ} \mathrm{C}$ (TR $\left.302-\mathrm{A}\right)$ had a porosity equivalent to the sample heated to $70{ }^{\circ} \mathrm{C}$ (TR311-3).

The measured porosity of $48 \%$ for the higher temperature mixes is very close to values reported in the literature for samples that have been cured for months at ambient conditions. This provides confidence that the method in this report of measuring porosity by heating the sample to $105{ }^{\circ} \mathrm{C}$ and measuring the mass loss does provide reasonable values for grout porosities.

The porosity maximum provided in Table 3-2 is a theoretical value calculated by dividing the volume of simulant introduced into a mix by the overall volume of grout (determined by the expected density) that will be produced from this mix after curing. The intent of introducing the porosity maximum is to provide a reference for the measured porosity to the expected porosity if no hydration reactions occurred. 
The last column in Table 3-2 presents the hydration $\mathrm{w} / \mathrm{cm}$ ratio. This ratio provides a quantitative value for the uptake of water through hydration reactions expressed in terms of the ratio of reacted water to the amount of cementitious material in the mix design. For example, the hydration $\mathrm{w} / \mathrm{cm}$ ratio is between 0.16 and 0.18 for OPC in water as determined by these measurements. It turns out that this is close to the maximum amount of hydration that will occur in this system. Therefore, for an OPC in water mix with an original w/cm ratio of 0.60 , much of the water has not reacted and resides in the pore volume (i.e., an amount of water expressed as 0.42 to $0.44 \mathrm{w} / \mathrm{cm}$ does not react in this system). Reduction of the $\mathrm{w} / \mathrm{cm}$ ratio in the mix design will reduce the amount of unreacted water and the porosity.

\subsection{Porosities of Grouts Prepared from OPC and GGBFS in MCU Simulant}

The porosities were also measured for mixes made using (1) OPC in MCU or DDA simulants and (2) GGBFS in MCU or DDA simulants at a w/cm ratio of 0.60 at $25{ }^{\circ} \mathrm{C}$. The porosities for OPC or GGBFS in MCU are provided in Tables 3-3 and 3-4.

Table 3-3 Porosities of Mixes Containing OPC in MCU Simulant as a Function of Curing Time

\begin{tabular}{|c|c|c|c|c|c|c|c|c|}
\hline Sample ID & Sample & Curing & Cure Time & Cured & w/cm & Porosity & Porosity & W/cm \\
\hline & Type & Temperature & Days & Density & Batched & Measured & Maximum & hydration \\
\hline TR 280 & MCU/OPC & Ambient & 14 & 1.905 & 0.60 & 57.7 & 70.5 & 0.11 \\
\hline TR 309 & MCU/OPC & Ambient & 22 & 1.911 & 0.60 & 59.3 & 70.7 & 0.10 \\
\hline TR 289 & MCU/OPC & Ambient & 23 & 1.891 & 0.60 & 56.3 & 70.0 & 0.12 \\
\hline TR 280 & MCU/OPC & Ambient & 37 & 1.905 & 0.60 & 54.2 & 70.5 & 0.14 \\
\hline TR 289 & MCU/OPC & Ambient & 98 & 1.891 & 0.60 & 52.5 & 70.0 & 0.15 \\
\hline TR 280 & MCU/OPC & Ambient & 160 & 1.905 & 0.60 & 49.7 & 70.5 & 0.18 \\
\hline
\end{tabular}

The porosities of the OPC/MCU mixes at shorter cure times are higher than the porosities measured for OPC in water. This is generally consistent with the results of heat of hydration reactions where the amount of heat produced by OPC/MCU mixes was less than the amount of heat produced by OPC in water. However, the data in Table 3-3 demonstrate that the porosity continues to decrease with time of curing which implies that the OPC is continuing to react with time. The hydration $\mathrm{w} / \mathrm{cm}$ ratio consequently increases with time reflecting the additional hydration reactions. 
Table 3-4 Porosities of Mixes Containing GGBFS in MCU Simulant as a Function of Curing Time

\begin{tabular}{|c|c|c|c|c|c|c|c|c|}
\hline Sample ID & Sample & Curing & Cure Time & Cured & w/cm & Porosity & Porosity & W/cm \\
\hline & Type & Temperature & Days & Density & Batched & Measured & Maximum & hydration \\
\hline TR 277 & MCU/GGBFS & Ambient & 14 & 1.861 & 0.60 & 57.4 & 68.9 & 0.10 \\
\hline TR 310 & MCU/GGBFS & Ambient & 16 & 1.864 & 0.60 & 57.7 & 69.0 & 0.10 \\
\hline TR 290 & MCU/GGBFS & Ambient & 23 & 1.843 & 0.60 & 57.9 & 68.2 & 0.09 \\
\hline TR 277 & MCU/GGBFS & Ambient & 37 & 1.861 & 0.60 & 57.3 & 68.9 & 0.10 \\
\hline TR 290 & MCU/GGBFS & Ambient & 98 & 1.843 & 0.60 & 53.3 & 68.2 & 0.13 \\
\hline TR 277 & MCU/GGBFS & Ambient & 160 & 1.861 & 0.60 & 54.5 & 68.9 & 0.12 \\
\hline
\end{tabular}

The initial porosities of the GGBFS/MCU mixes are also higher compared to values of porosity for OPC in water and roughly equivalent to the initial porosities of OPC in MCU mixes.

However, in these mixes, the hydration reactions do not continue with time to the extent that was evident with OPC in MCU. This is also evident by the values of the hydration $\mathrm{w} / \mathrm{cm}$ ratio as a function of time.

The porosities of mixes using either OPC or GGBFS in DDA simulants are reported in Table 35. The initial porosities of both the OPC and GGBFS in DDA simulant mixes were essentially equivalent to the porosities of OPC and GGBFS in MCU simulants.

Table 3-5 Porosities of Mixes Containing Either OPC or GGBFS in DDA Simulant

\begin{tabular}{|c|c|c|c|c|c|c|c|c|}
\hline Sample ID & Cementitious & Curing & Cure Time & Cured & w/cm & Porosity & Porosity & W/cm \\
\hline DDA & Material & Temperature & Days & Density & Batched & Measured & Maximum & hydration \\
\hline TR 281 & OPC & Ambient & 14 & 1.867 & 0.60 & 57.7 & 69.0 & 0.10 \\
\hline TR 281 & OPC & Ambient & 37 & 1.867 & 0.60 & 54.9 & 69.0 & 0.13 \\
\hline TR 278 & GGBFS & Ambient & 14 & 1.833 & 0.60 & 57.5 & 68.3 & 0.09 \\
\hline TR 278 & GGBFS & Ambient & 37 & 1.833 & 0.60 & 57.8 & 70.7 & 0.09 \\
\hline
\end{tabular}

\subsection{Porosities of Grouts Prepared from Premix in DDA, MCU and SWPF Simulants}

The grout formulations for Saltstone mixes typically use a cementitious material mixture (premix) made up of $45 \%$ GGBFS, $45 \%$ FA and $10 \%$ OPC at $25^{\circ} \mathrm{C}$. The measured and maximum porosities are presented in Tables 3-6, 3-7 and 3-8 for samples prepared during the grout variability study for MCU, DDA and SWPF mixes made with premix. 
Table 3-6 Results of the Measured Porosity and Maximum Porosity for Mixes Made from Premix and DDA Simulant at $25^{\circ} \mathrm{C}$

\begin{tabular}{|c|c|c|c|c|c|c|c|c|}
\hline Sample ID & Curing & Curing & Cure Time & Cured & w/cm & Porosity & Porosity & W/cm \\
\hline DDA & Conditions & Temperature & Days & Density & Batched & Measured & Maximum & hydration \\
\hline GVS 23 & Sealed & Ambient & 310 & 1.773 & 0.60 & 58.15 & 65.82 & 0.07 \\
\hline GVS 24 & Sealed & Ambient & 310 & 1.755 & 0.62 & 60.63 & 66.49 & 0.05 \\
\hline GVS 25 & Sealed & Ambient & 310 & 1.754 & 0.62 & 59.08 & 66.17 & 0.06 \\
\hline GVS 26 & Sealed & Ambient & 310 & 1.781 & 0.58 & 58.96 & 64.84 & 0.05 \\
\hline GVS 27 & Sealed & Ambient & 310 & 1.812 & 0.58 & 59.58 & 66.01 & 0.06 \\
\hline GVS 28 & Sealed & Ambient & 310 & 1.778 & 0.60 & 58.37 & 66.01 & 0.07 \\
\hline GVS 29 & Sealed & Ambient & 303 & 1.767 & 0.58 & 56.32 & 64.04 & 0.07 \\
\hline GVS 30 & Sealed & Ambient & 303 & 1.805 & 0.62 & 59.30 & 68.26 & 0.08 \\
\hline GVS 31 & Sealed & Ambient & 303 & 1.777 & 0.62 & 62.41 & 67.24 & 0.04 \\
\hline GVS 32 & Sealed & Ambient & 303 & 1.796 & 0.58 & 60.49 & 65.70 & 0.05 \\
\hline GVS 33 & Sealed & Ambient & 303 & 1.769 & 0.60 & 58.48 & 65.67 & 0.06 \\
\hline \multicolumn{2}{|l|}{} & & & & & & & \\
\hline 3 Identical Batches & & & & & & & \\
\hline
\end{tabular}

Table 3-7 Results of the Measured Porosity and Maximum Porosity for Mixes Made from Premix and MCU Simulant at $25^{\circ} \mathrm{C}$

\begin{tabular}{|c|c|c|c|c|c|c|c|c|}
\hline Sample ID & Curing & Curing & Cure Time & Cured & w/cm & Porosity & Porosity & W/cm \\
\hline MCU & Conditions & Temperature & Days & Density & Batched & Measured & Maximum & hydration \\
\hline GVS54 & Sealed & Ambient & 50 & 1.79 & 0.60 & 61.71 & 66.07 & 0.04 \\
\hline GVS55 & Sealed & Ambient & 38 & 1.74 & 0.65 & 64.08 & 67.04 & 0.03 \\
\hline GVS55 & Sealed & Ambient & 100 & 1.74 & 0.65 & 64.00 & 67.04 & 0.03 \\
\hline GVS56 & Sealed & Ambient & 39 & 1.82 & 0.55 & 60.83 & 64.32 & 0.03 \\
\hline GVS57 & Sealed & Ambient & 100 & 1.77 & 0.65 & 64.25 & 68.43 & 0.04 \\
\hline GVS58 & Sealed & Ambient & 39 & 1.77 & 0.65 & 64.64 & 68.35 & 0.04 \\
\hline GVS59 & Sealed & Ambient & 101 & 1.81 & 0.55 & 59.85 & 64.01 & 0.04 \\
\hline GVS60 & Sealed & Ambient & 39 & 1.77 & 0.65 & 64.72 & 68.20 & 0.03 \\
\hline GVS61 & Sealed & Ambient & 101 & 1.78 & 0.60 & 62.64 & 66.00 & 0.03 \\
\hline GVS62 & Sealed & Ambient & 101 & 1.81 & 0.55 & 60.86 & 64.04 & 0.03 \\
\hline
\end{tabular}


Table 3-8 Results of the Measured Porosity and Maximum Porosity for Mixes Made from Premix and SWPF Simulant at $25^{\circ} \mathrm{C}$

\begin{tabular}{|c|c|c|c|c|c|c|c|c|}
\hline Sample ID & Curing & Curing & Cure Time & Cured & w/cm & Porosity & Porosity & W/cm \\
\hline SWPF & Conditions & Temperature & Days & Density & Batched & Measured & Maximum & hydration \\
\hline GVS63 & Sealed & Ambient & 28 & 1.82 & 0.60 & 61.95 & 66.54 & 0.04 \\
\hline GVS64 & Sealed & Ambient & 28 & 1.78 & 0.62 & 61.54 & 66.72 & 0.05 \\
\hline GVS65 & Sealed & Ambient & 28 & 1.82 & 0.62 & 62.05 & 67.24 & 0.05 \\
\hline GVS66 & Sealed & Ambient & 28 & 1.78 & 0.58 & 59.54 & 63.88 & 0.04 \\
\hline GVS67 & Sealed & Ambient & 28 & 1.82 & 0.58 & 59.96 & 65.17 & 0.05 \\
\hline GVS68 & Sealed & Ambient & 21 & 1.79 & 0.60 & 61.12 & 65.60 & 0.04 \\
\hline GVS69 & Sealed & Ambient & 14 & 1.78 & 0.58 & 60.61 & 63.46 & 0.03 \\
\hline GVS70 & Sealed & Ambient & 14 & 1.82 & 0.62 & 65.75 & 67.93 & 0.02 \\
\hline GVS71 & Sealed & Ambient & 14 & 1.75 & 0.62 & 62.20 & 65.27 & 0.03 \\
\hline GVS72 & Sealed & Ambient & 14 & 1.79 & 0.58 & 61.11 & 64.83 & 0.03 \\
\hline GVS73 & Sealed & Ambient & 14 & 1.80 & 0.60 & 61.49 & 65.66 & 0.04 \\
\hline \multicolumn{2}{|l|}{} & & & & & & & \\
\hline 3 Identical Batches & & & & & & & \\
\hline
\end{tabular}

For mixes of MCU and SWPF in premix, the porosities center about $62 \%$ with an uptake of water through hydration reactions equivalent to a $\mathrm{w} / \mathrm{cm}$ ratio of 0.04 . For DDA and premix, the porosity is slightly lower at $57 \%$ with an uptake of water through hydration reactions equivalent to a $\mathrm{w} / \mathrm{cm}$ ratio of 0.07 . These porosities are closer to the maximum porosities than for the porosities of OPC in water or for OPC or GGBFS in MCU and DDA simulants.

From the data in Tables 3-6 and 3-7, it is evident that the batch-to-batch reproducibility is reasonable for these samples for both the total porosity and the cured grout density.

Analysis of the data shows that the time of curing does not appear to play a significant role in the measured porosity values for these mixes. For example, the porosity values for premix in DDA do not change significantly over the period of $\sim 1$ year for mixes maintained at ambient temperature under sealed conditions.

\subsection{Comparison of TGA and Mass Loss at $105^{\circ} \mathrm{C}$}

A comparison of the mass loss by heating to $105{ }^{\circ} \mathrm{C}$ with data from TGA was made for several samples. For example, the mass loss of the baseline MCU simulant grout mix was determined using TGA by increasing the temperature to $105{ }^{\circ} \mathrm{C}$ and then holding at this temperature until no further mass change occurred. Then the temperature was increased to $\sim 800{ }^{\circ} \mathrm{C}$ (Figure $3-1$ ) to monitor any additional mass loss. The mass loss of $29.52 \%$ at $105{ }^{\circ} \mathrm{C}$ with the TGA measurement is within experimental error of the values achieved by using the Mettler Moisture Analyzer. The additional mass loss at higher temperatures is a combination of water loss associated with the dehydration of calcium silicate hydrate $(\mathrm{CSH})$ particles, nitrate/nitrite destruction, decarbonation of $\mathrm{CaCO}_{3}$ and dehydration of $\mathrm{Ca}(\mathrm{OH})_{2}$. 


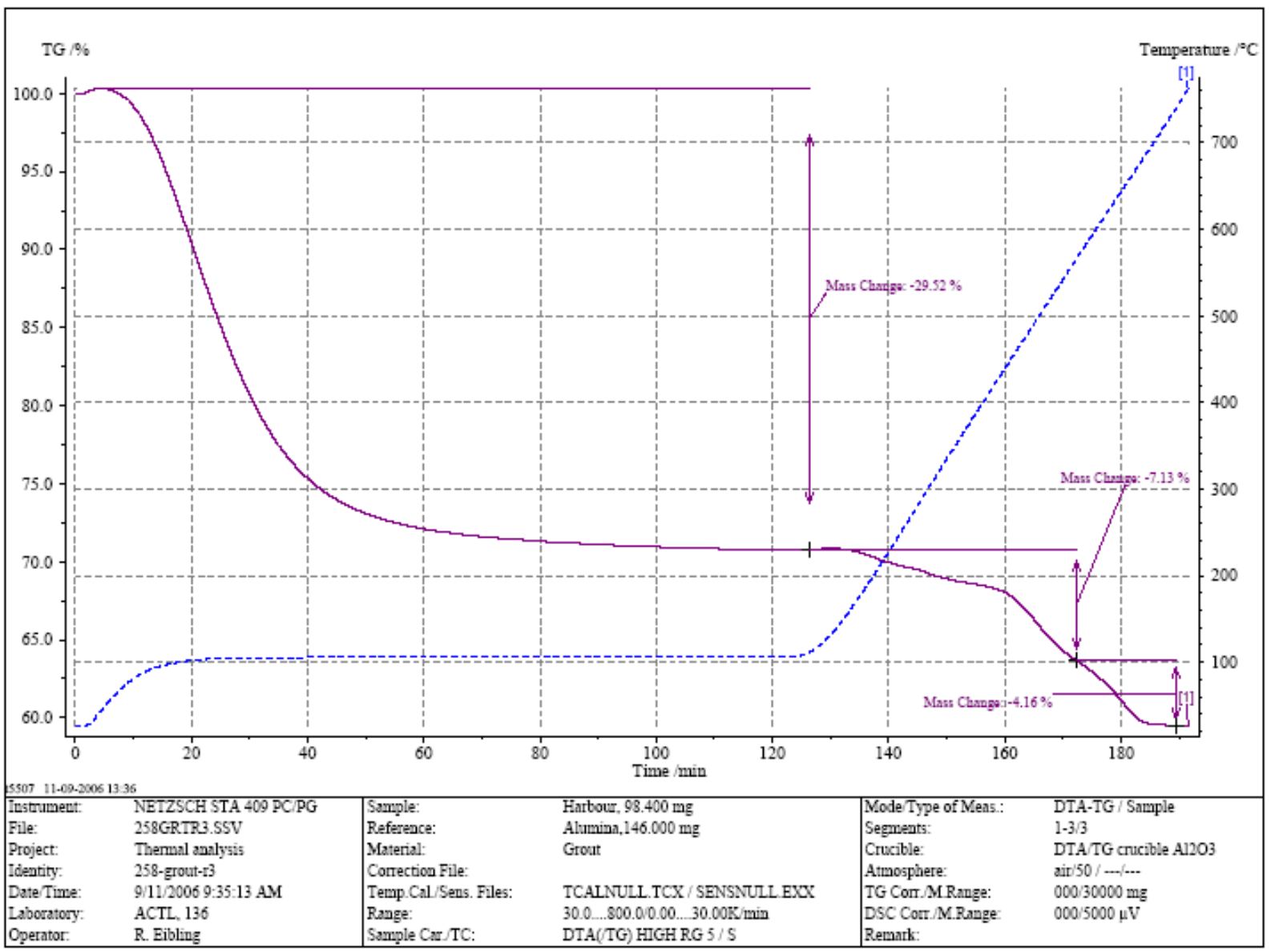

Figure 3-1 TGA results for TR258 sample of premix and MCU simulant at $0.60 \mathrm{w} / \mathrm{cm}$ ratio

The contribution to mass loss at higher temperatures from the nitrate and other components of the simulant is revealed in Figure 3-2 for a sample of premix in water without any dissolved salts. There is relatively little mass loss at the higher temperatures for this system. 


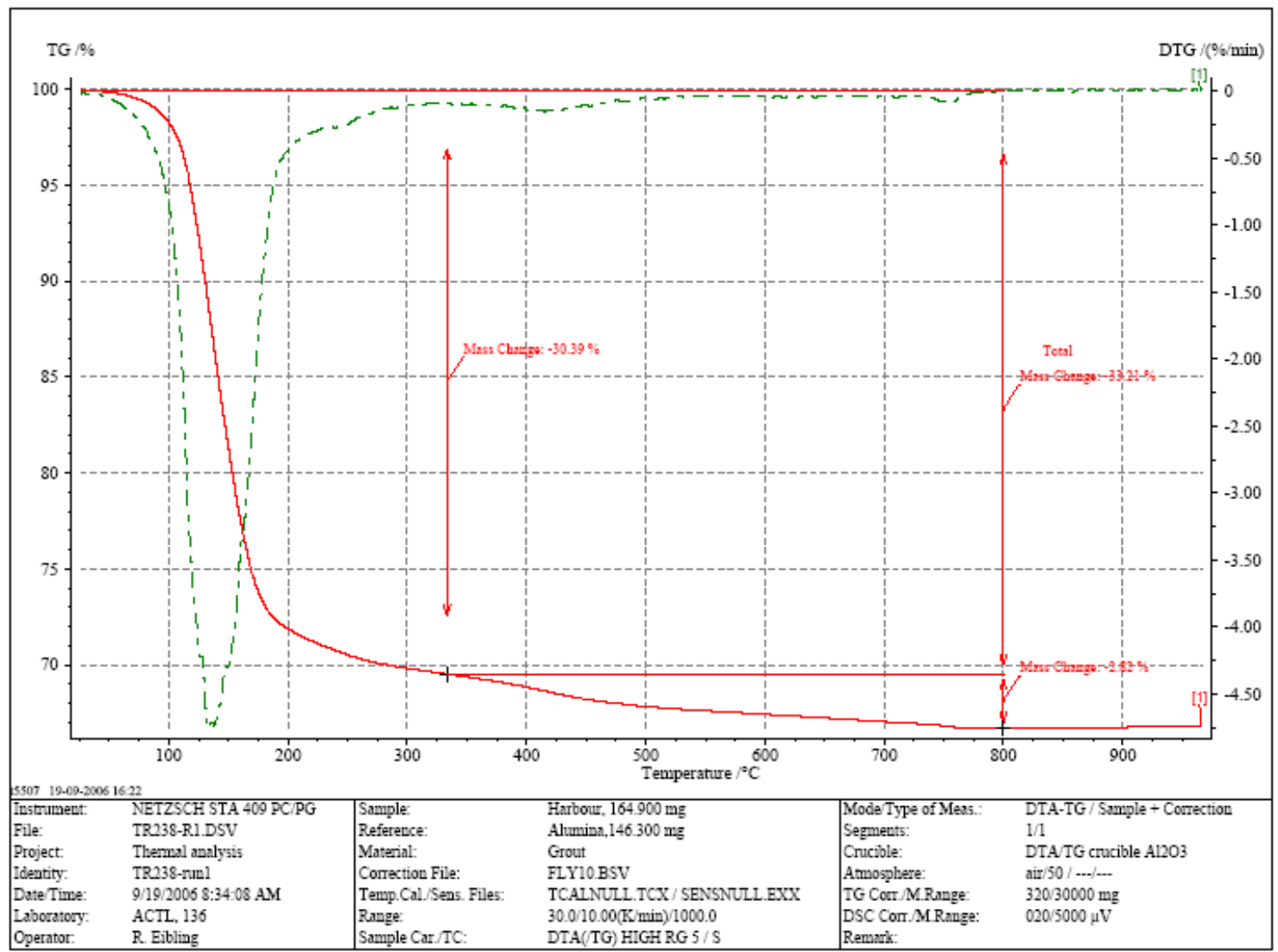

Figure 3-2 TGA results for a premix in water grout

Finally, a comparison between TGA analysis of a sample of GVS 54 using argon or air revealed no significant difference in mass loss. This was performed to determine whether carbon dioxide in the air can affect the results of the mass loss experiments.

\subsection{Modeling of Porosity - Saltstone Variability Study}

The objective for measurement of the porosity in the Saltstone Variability Study is to determine the sensitivity of the porosity to the projected chemical and processing variations experienced under normal operating conditions at Saltstone Production Facility (SPF). As part of this study, the porosities and cured grout densities were measured for the mixes that comprised Phase III (DDA), Phase V (MCU) and Phase VI (SWPF) of the Variability Study. The porosities and cured grout densities are provided in Tables 3-6, 3-7 and 3-8.

These data were statistically evaluated to determine whether a linear model could be developed for the total porosity as a function of the variables tracked. Figure 3-3 shows the linear model that was developed with an $\mathrm{R}^{2}$ of 0.74 and no statistical evidence for a lack of fit. The equation corresponding to this empirical fit is: 


$$
\text { Total Porosity }\left(\text { volume \%) }=29.7+42.9[\mathrm{w} / \mathrm{cm}]+1.0\left[\mathrm{OH}^{-}\right]+1.5\left[\mathrm{NO}_{3}{ }^{-}+\mathrm{NO}_{2}{ }^{-}\right]\right.
$$

where $\mathrm{w} / \mathrm{cm}$ is the water to cementitious material ratio of the mix, $\left[\mathrm{OH}^{-}\right]$is the concentration of free hydroxide ion in moles/liter, and $\left[\mathrm{NO}_{3}{ }^{-}+\mathrm{NO}_{2}{ }^{-}\right]$is the nitrate plus nitrite concentration in moles/liter.

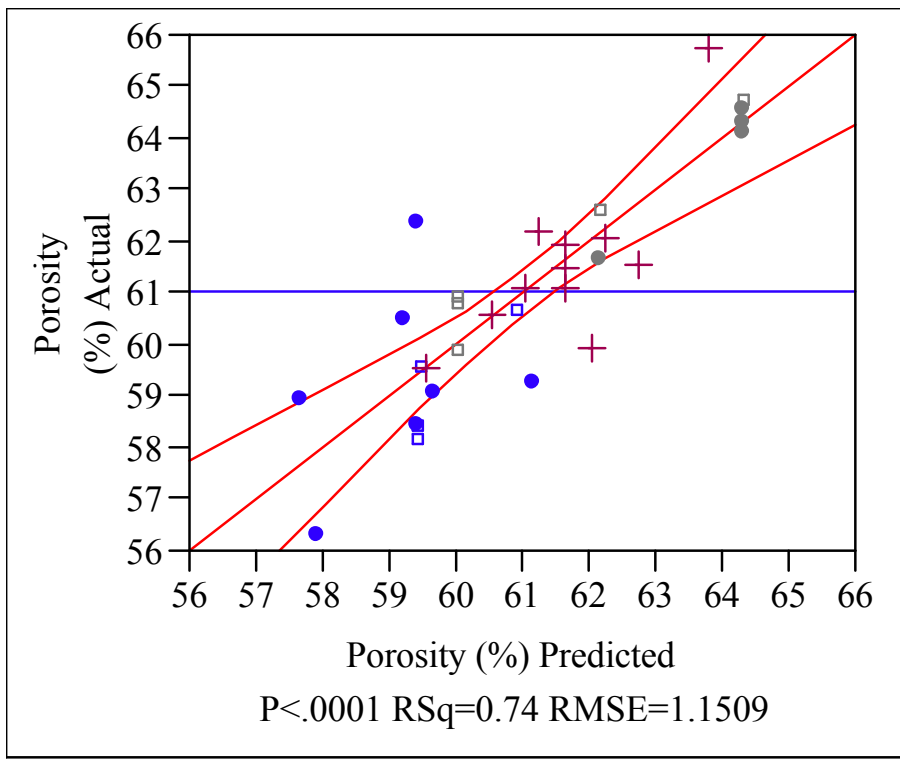

Figure 3-3 Linear model for the total porosity as a function of $\mathrm{w} / \mathrm{cm}$, free hydroxide ion concentration and total nitrate plus nitrite concentration measured at $25^{\circ} \mathrm{C}$

It is clear from the model that the $\mathrm{w} / \mathrm{cm}$ ratio is important to the porosity value. This has also been observed by others [12]. The Phase V data for MCU in which the chemical composition of the simulant was maintained and only changes in $\mathrm{w} / \mathrm{cm}$, temperature and percent OPC were introduced, is plotted as a function of the w/cm ratio in Figure 3-4. From these data it can be observed that the porosity changes from $\sim 60$ to $65 \%$ as the $\mathrm{w} / \mathrm{cm}$ ratio is increased from 0.55 to 0.65 


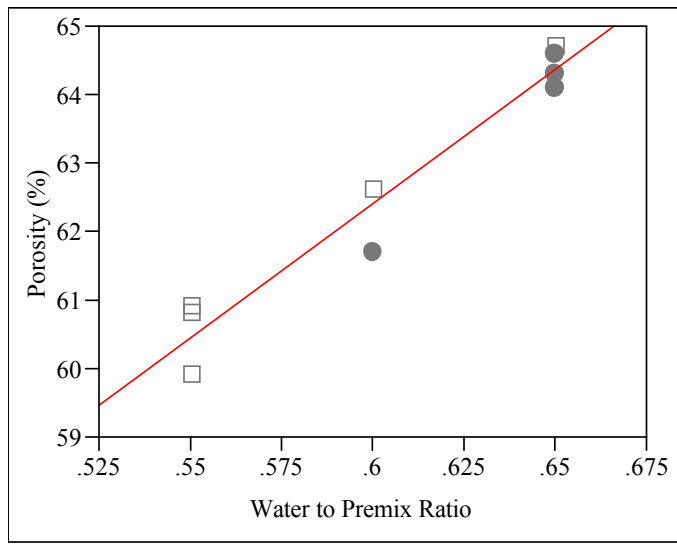

Figure 3-4 Linear dependence of the porosity for MCU based simulant mixes on the w/cm ratio at $25^{\circ} \mathrm{C}$

\subsection{Extent of Reaction}

The extent of hydration reactions can be estimated from the heat of hydration measurements [13]. That is, the greater the amount of heat generated per gram of cementitious material, the greater the extent of reaction. Comparing the results of the heat of hydration to the porosities as measured in this report indicates that the greater the heat of hydration, the less the porosity of the mix. This makes sense in that the $\mathrm{CSH}$ gel that forms as a result of hydration reactions fills the pore space.

An example of this trend (Figure 3-5) can be seen by plotting the porosity against the heat of hydration for mixes having the same water to cementitious ratio $(0.60)$. The data include OPC in water, OPC in MCU and premix in MCU (see Table 3-10). Due to the fact that OPC continues to react with time in these systems, the data used were chosen to best match the 7 day heat of hydration tests.

\section{Table 3-9 Heat of Hydration, Porosity and Hydration w/cm ratio}

\begin{tabular}{|c|c|c|c|c|}
\hline Cementious & Medium & Porosity & Heat of & W/cm \\
\hline Material & & Measured & Hydration $(\mathrm{J} / \mathbf{g ~ c m})$ & hydration \\
\hline OPC & Water & 52.0 & 355 & 0.16 \\
\hline OPC & MCU & 57.5 & 251 & 0.11 \\
\hline Premix & MCU & 62.0 & 120 & 0.04 \\
\hline
\end{tabular}




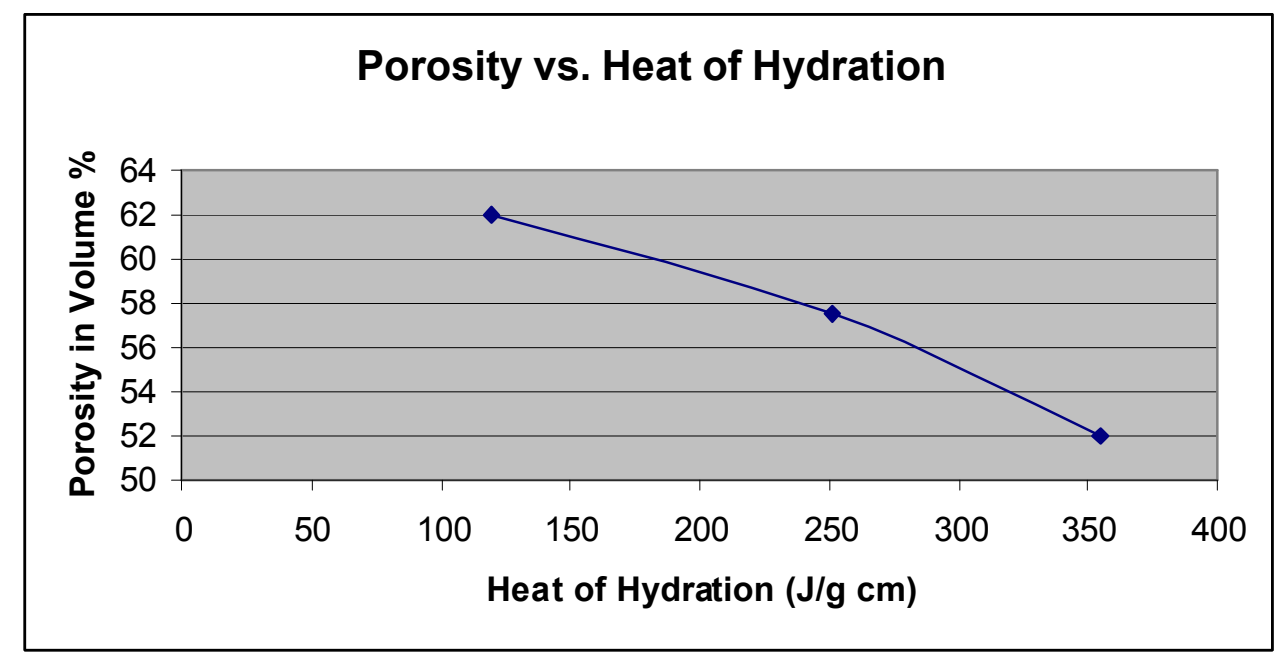

Figure 3-5 Porosity vs. heat of hydration in Joules/gram of cementitious material

The heat of hydration values can be plotted versus the extent of reaction as reflected by the amount of water that has actually reacted with the cementitious material in the mix. This is referred to as the hydration w/cm ratio. Figure 3-6 provides this plot for the data in Table 3-7.

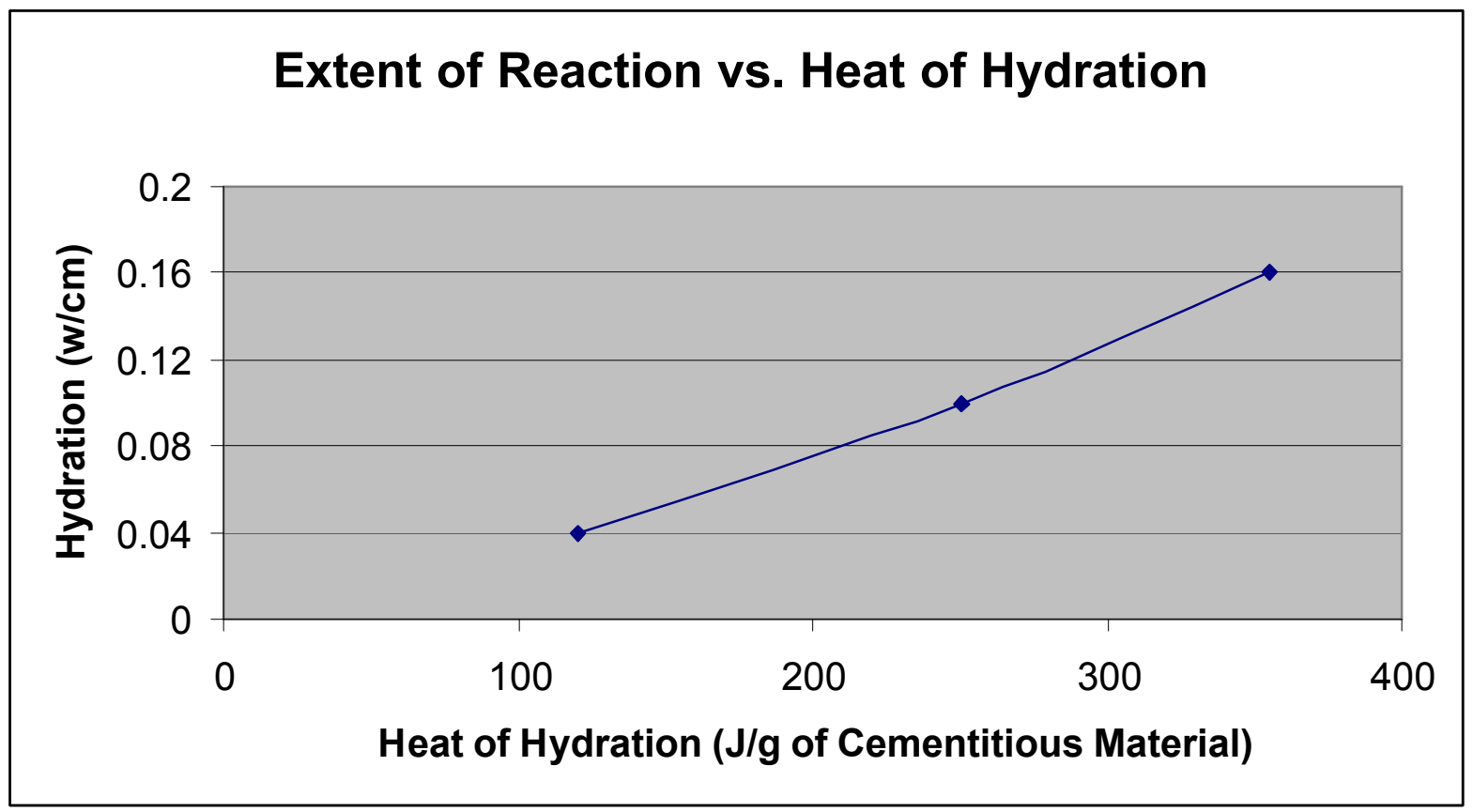

Figure 3-6 Plot of extent of reaction (expressed here as the hydration w/cm ratio) vs. heat of hydration in Joules/gram of cementitious material 
The conclusion from these data is that the porosities are relatively high for the simulated mixes due to the low reactivity of the premix in the simulants. As suggested in a previous report [13], this most likely results from the low reactivity of the fly ash.

The extent of reaction can also be examined from a mass perspective. Table 3-11 provides similar data on a mass basis and shows the amount of water that has reacted with the cementitious materials to form the CSH structure with grout properties and the amount of water that remains in the pores (free water).

Table 3-10 The Percentages of Free Water and Bound Water in the Grout Mixes Prepared at $0.60 \mathrm{w} / \mathrm{cm}$ and $25^{\circ} \mathrm{C}$

\begin{tabular}{|c|c|c|c|c|}
\hline Sample ID & Type & Cure Time & Free $\mathrm{H}_{2} \mathrm{O}$ & Bound $\mathrm{H}_{2} \mathrm{O}$ \\
\hline & & Days & $\%$ & $\%$ \\
\hline GVS 54 & MCU & 50 & 93.4 & 6.6 \\
\hline GVS 54 & MCU & 22 & 94.3 & 5.7 \\
\hline GVS 34 & DDA & 98 & 87.7 & 12.3 \\
\hline GVS 34 & DDA & 22 & 88.5 & 11.5 \\
\hline GVS 63 & SWPF & 30 & 93.0 & 7.0 \\
\hline GVS 73 & SWPF & 15 & 93.5 & 6.5 \\
\hline
\end{tabular}

For MCU and SWPF mixes, the results show that $\sim 6 \%$ of the introduced water reacts to produce hydration products while close to $10 \%$ on average of the introduced water reacts to produce hydration products with DDA simulants. 


\subsection{CONCLUSIONS}

This report presents the development of the technique, and the results of the measurements of total porosity and cured grout density for grout mixes based on simulated projections of future batches. The conclusions from this study are:

- A method for measurement of porosity was developed that involves the heating of the sample at $105{ }^{\circ} \mathrm{C}$ until no further mass loss is observed. This mass loss value is then used to calculate the volume percent porosity of the mix.

- The method selected uses a Mettler Toledo HR83 Moisture Analyzer that is already operational at ACTL. The method is cost effective with measurement times on the order of 30 to 60 minutes per sample.

- The results of mass loss at $105^{\circ} \mathrm{C}$ were compared to the results obtained using TGA to demonstrate consistency between the two approaches.

- Validation of this method was demonstrated by comparing measurements of mass loss at $105{ }^{\circ} \mathrm{C}$ for cured OPC in water mixes to values presented in the literature for this system (results were essentially equivalent).

- A stereopycnometer from Quantachrome Instruments was selected to measure the cured grout densities. This equipment was already operational at ACTL and was calibrated using a solid stainless steel sphere of known volume.

- Essentially complete hydration of OPC in water results in a porosity of $47 \%$ and an uptake of water through hydration reactions equivalent to a $\mathrm{w} / \mathrm{cm}$ ratio of 0.18 .

- Reactions of OPC or GGBFS in MCU and DDA simulants result in cured mixes having higher porosities than $47 \%$ reflecting incomplete hydration with an uptake of water through hydration reactions equivalent to a $\mathrm{w} / \mathrm{cm}$ ratio of 0.10 to 0.12 .

- For OPC in MCU or DDA, the hydration reactions continue with time resulting in a continual decrease in porosity. This effect is much less pronounced for GGBFS in either of these simulants.

- For mixes of DDA, MCU and SWPF in premix the extent of reaction is further reduced and the resulting porosities for the three batches are much higher and approach the theoretical maximum porosities.

- For mixes of MCU and SWPF in premix, the porosities center about $62 \%$ with an uptake of water through hydration reactions equivalent to a w/cm ratio of 0.04 . For DDA and premix, the porosity is slightly lower at $57 \%$ with an uptake of water through hydration reactions equivalent to a $\mathrm{w} / \mathrm{cm}$ ratio of 0.07 .

- For mixes of DDA, MCU and SWPF in premix, the hydration reactions do not appreciably continue with time under sealed conditions at room temperature.

- The extent of reaction, as measured previously on these systems by isothermal calorimetry, is inversely proportional to the measured porosities of the mixes.

- The extent of reaction, as measured previously on these systems by isothermal calorimetry, correlates well with the uptake of water through hydration reactions as expressed by the hydration $\mathrm{w} / \mathrm{cm}$ ratio. 
- Modeling of three of the statistically designed phases of the Saltstone Variability Study demonstrated that the data could be fit to a linear model with an $\mathrm{R}^{2}$ of 0.74 and no statistical evidence for a lack of fit.

- The model revealed that the $\mathrm{w} / \mathrm{cm}$ ratio plays a significant role in the total porosity with porosity increasing as the $\mathrm{w} / \mathrm{cm}$ ratio increases. Other elements of the model include the free hydroxide ion concentration and the total nitrate plus nitrite ion concentration.

- The $\mathrm{w} / \mathrm{cm}$ ratio for a series of mixes in which the composition of the salt solution remained constant (MCU baseline) changed the porosity from $\sim 60$ to $65 \%$ as the $\mathrm{w} / \mathrm{cm}$ ratio went from 0.55 to 0.65 .

\subsection{PATH FORWARD}

The measurement of permeability or in this case the hydraulic conductivity, for these mixes is an important next step because it is an input parameter to the Performance Assessment modeling for Saltstone. These measurements are especially difficult for the very low hydraulic conductivities that are anticipated for these mixes. If the pores within a mix are connected (which tends to occur for mixes with higher porosity), then conductivity of a fluid can occur unimpeded through the pore structure (referred to as percolation). Therefore, if a correlation between hydraulic conductivity and the total porosity is established, it will be far easier to determine which factors control the hydraulic conductivity. Establishing an acceptance criterion based on porosity as measured in this report has the potential to provide a routine method to ensure that simulated and/or radioactive mixes comply with requirements.

\subsection{REFERENCES}

[1] Scoping Studies for Development of Saltstone Variability Study, J. R. Harbour and T. B. Edwards, WSRC-RP-2005-01439, Rev. 0, 2005.

[2] Cement Chemistry, H. F. W. Taylor, $2^{\text {nd }}$ Edition, Thomas Telford, 1997.

[3] Studies of the Physical Properties of Hardened Portland Cement Paste, T. C. Powers, and T. L. Brownyard, J. Am. Concrete Inst. 43, 1947

[4] R. F. Feldman, Cement Technol. 3, 1972.

[5] Hydraulic Property Data Package for the E-Area and Z-Area Soils, Cementitious Materials, and Waste Zones, M. A. Phifer, M. R. Millings and G. P. Flach, WSRC-STI-200600198, Rev. 0, 2006.

[6] Mercury Porosimetry, an Inappropriate Method for the Measurement of Pore Size Distributions in Cement-Based Materials, S. Diamond, Cem. Concr. Res., 30, 2000. 
[7] Curing, Hydration, and Microstructure of Cement Paste, D. P. Bentz and P. E. Stutzman, ACI Materials Journal, 103-M39, 2006.

[8] Modeling Relationships Between Permeability and Cement Paste Pore Microstructures, J. H. D. Hampton and M. D. A. Thomas, Cem. Concr. Res., 23, 1993.

[9] Effect of Drying on Cement-Based Materials Pore Structure as Identified by MIP. A Comparative Study between Oven, Vacuum and Freeze Drying, C. Galle, Cem. Concr. Res. 31, 2001.

[10] Characterization of Slag, Fly Ash, and Portland Cement for Saltstone, J. R. Harbour, E. K. Hansen, T. B. Edwards, V. J. Williams, R. E. Eibling, D. R. Best and D. M. Missimer. WSRC-TR-2006-00067, Rev. 0, 2006.

[11] Variability Study for Saltstone, J. R. Harbour, T. B. Edwards, E. K. Hansen and V. J. Williams, WSRC-TR-2005-00447, October 2005.

[12] Measurement of Porosity in Blended Cement Pastes, R. L. Day and B. K. Marsh, Cem. Concr. Res., 18, 1988.

[13] Heat of Hydration of Saltstone Mixes - Measurement by Isothermal Calorimetry, J. R. Harbour, V. J. Williams and T. B. Edwards, WSRC-STI-2007-00263, Rev. 0, 2007. 